\title{
Measuring Rural Poverty and Inequality Among Rural Households in Gedeo Zone, SNNP Region, Ethiopia
}

\author{
Berhanu Getinet Kibret(Asst. Professor) \\ Department Of Economics, Hawassa University, Ethiopia
}

\begin{abstract}
Poverty is a complex and has multidimensional feature. It involves people experiencing various degrees of material deprivation, the concept is used to cover a wide ranging set of interrelated life chances. The purpose of this study was to measure poverty in rural Gedeo zone, southern Ethiopia with specific objectives of measuring poverty and inequality among the rural households. The research was undertaken using a cross sectional design on a random sample of 325 households in the study area. The sample size was determined based on multi stage sampling procedure. In order to achieve its objective, primary data was collected through survey and interview using semi structured questionnaires. Analysis of data was made after the data collection. In this regard, the Cost of Basic Needs (CBN ) approach and FGT measures were employed to set the poverty line and compute the magnitude of rural poverty in the study respectively. The food and absolute poverty lines were calculated based on food basket of $2200 \mathrm{Kcal}$ per adult per day. Accordingly, the food and absolute poverty lines for the study area were determined to be Birr 3952.74 and 4463.35, respectively. The food expenditure takes the lion's share accounting for about $88.56 \%$ (relative to the non-food expenditure) in the consumption expenditure of the poor and thus this substantial expenditure was used for estimating the poverty line. Thereafter, the poverty indices were computed using FGT indices. The incidence, depth and severity of food poverty stood at $0.052,0.021$ and 0.010 respectively, while respective measures for absolute poverty were found to be $0.302,0.085$ and 0.034 . These measures indicated that poverty and inequality significantly prevails in the study area. All the measures confirm that poverty and inequality have been problems and remain major concern in rural development agenda in Ethiopia. Thus, rural poverty and inequality alleviation in the study area in particular and rural Ethiopia in general requires context based policies and adoption of strategies to alleviate poverty and inequality among the rural households.
\end{abstract}

Keywords: Rural Households, Poverty, Inequality, CBN, FGT, Gedeo zone, Ethiopia

DOI: $10.7176 /$ JPID/52-03

Publication date: January $31^{\text {st }} 2020$

\section{INTRODUCTION}

The world has witnessed phenomenal advances in science, technology and wealth creation. Despite this, poverty in all its manifestations remains deep, pervasive and intractable. Poverty is a situation in which the underprivileged do not have adequate food and shelter, lack access to education and health services, are exposed to violence, and find themselves in a state of unemployment, vulnerability and powerlessness (Todaro, 1997). Poverty is multi-dimensional and has to be looked at through a variety of indicators such as levels of income and consumption, social indicators and indicators of vulnerability to risks and socio-political access and participation. The most common approach to the measurement of poverty is based on incomes or consumption levels. It is widely understood that an individual is considered poor if consumption or income level falls below some minimum level necessary to meet basic needs which is a poverty line (World Bank,2004).

With the increased awareness and availability of data, various measures of poverty have been developed overtime. The most widely used poverty indices are the incidence of poverty (headcount), the poverty gap (depth of poverty), and the poverty severity (measures income inequality among the poor)(Kimalu et al.,2002). The headcount index indicates the share of the population whose income or consumption is below the poverty line. But it does not show how far below the poverty line the poor. Also, it forces the overall poverty index to remain constant even when the welfare of the poor has improved or worsened. Beside, with this index, an income transfer from an extremely poor person to a person just below the poverty line would show a reduction in poverty despite the decline in the income of the extremely poor (Kimalu et al.,2002). On the other side, depth of poverty index provides information regarding how far households are from the poverty line. This measure captures the mean aggregate consumption shortfall relative to the poverty line across the whole population. It measures the intensity of poverty by averaging the distance between the expenditure of the poor persons and the poverty line. This index can be used to estimate the resources that would bring the expenditure of every poor person up to the poverty line thereby eliminating absolute poverty (Aigbokhan, 2000) but it does not differentiate the degree of inequality among the poor when it is used to assess welfare (Kimalu et al., 2002). The Poverty severity index takes into account not only the distance separating the poor from the poverty line but also the inequality among the poor. It is the poverty index that shows the severity of poverty by squaring the gap between the expenditure of the poor individual and the poverty line. Because the index gives more weight to the 
poverty of the poorest, it measures the degree of inequality among the poor implying that transferring income to the poorest from the better-off poor should lower the poverty index (MEDaC, 1999).

Poverty and inequality are predominantly a rural phenomenon in the majority of Saharan-Africa countries. Approximately 75 percent of the world's poor reside in rural areas, and at current trends, the global percentage of the poor in rural areas will not fall below 50 percent before 2035 (Ravallion, 2000). The majority of the Ethiopians have been living in rural areas and agriculture is the main stay of the economy and at present, about $72.7 \%$ of the country's population engages in various agricultural activities and generates its income for consumption. The sector contributes $34.9 \%$ to the country's GDP next to service sector, which of course contributes 39.2 percent of GDP (NBE, 2017). The number of poor people in rural areas of Ethiopia exceeds the capacity of agriculture to provide sustainable livelihood opportunities due to low productivity, production and market linkages challenges. As a result, a significant proportion of the rural households face food insecurity and lives in poverty. In this regard, it has been shown that the proportion of food poor people are 34.7 percent in rural areas (MOFED, 2012). However, the current government of Ethiopia has formulated policies, and committed itself to growth and transformation plans which target sustainably improving rural livelihoods and national food security; but, there are no large-scale improvements in the living conditions of rural populations and the mass live in poverty (NPC, 2017). This calls for researching rural poverty and then design a policy for poverty alleviation and to bring improvements of lives of the poor.

\section{STATEMENT OF THE PROBLEM}

Ethiopian government has started the fight against poverty and demonstrated a strong commitment to poverty reduction by adopting its implementation of the integrated development plans; the Sustainable Development and Poverty Reduction Program (SDPRP) in 2002 its "plan for accelerated and sustainable development to end poverty (PASDEP) in 2006 and The Growth and Transformation Plan (GTP) in 2010(MOFED, 2012). There has been robust and sustained growth over the last 15 year that is witnessed by the recently registered economic growth of 7.7 percent in 2017. The growth recorded has led to improvements in income inequality and poverty reduction. The per capita income has continuously increased and reached USD 883(which is about 2.4 per day) in the same period (NBE, 2017) though it is far lower than the average per capita income for the Sub-Saharan Africa(SSA) which was \$ USD 1661 in the same year( World Bank,2017)

However, studies indicate that poverty and inequality among the poor remain challenges in Ethiopia that rural areas harbor the bulk of the poor; poverty and inequality have been unambiguously a rural phenomena. In line with this, the study conducted by MoFED (2012) indicated that national level absolute poverty head count index was $0.296(29.6 \%)$. The poverty gap index was estimated to be $0.078(7.8 \%)$ while it was $0.08(8.0 \%)$ for rural areas and $0.069(6.9 \%)$ for urban areas. Similarly, the national level poverty severity index(inequality) stood at $0.031(3.1 \%)$ with rural poverty severity index of $0.032(3.2 \%)$ being slightly higher than that of urban areas which was $0.027(2.7 \%)$. Beside, the proportion of food poor people (food poverty head count index) in the country was estimated to be $0.336(33.6 \%)$ while it stood at $0.347(34.7 \%)$ in rural areas and $0.279(27.9 \%)$ in urban areas. The food poverty gap index was estimated to be $0.105(10.5 \%)$ while it was $0.111(11.1 \%)$ for rural areas and $0.073(7.3 \%)$ for urban areas. Similarly, the national food poverty severity index stood at $0.046(4.6 \%)$ with rural food poverty severity index (inequality) of $0.05(5 \%)$ being slightly higher than that of urban areas $0.029(2.9 \%)$. Hence, the urgency of researching rural poverty and inequality is beyond doubt. The available body of literature is not only scanty and up-to-date but also far from being exhaustive; what have so far been studied in Ethiopia concentrate on and reflect the national picture which do not necessarily reflect the situation at grassroots levels and this fact is strongly supported by Dercon and Krishnan (1998). This research; therefore aims to measure poverty and inequality among rural households in Gedeo zone, southern Ethiopia.

\section{RESEARCH QUESTIONS}

The research questions to guide the study include:

- How much is the absolute (food and non-food ) poverty line for Gedeo Zone ?

- What are levels of poverty and inequality (the incidence, depth and severity) in the study area?

\section{OBJECTIVES OF THE STUDY}

- To determine the absolute (food + non-food) poverty line for Gedeo Zone

- To investigate the poverty and inequality levels(the incidence, depth and severity) in the study area

\section{SIGNIFICANCE OF THE STUDY}

Any intervention to alleviate and ultimately eliminate poverty needs a thorough understanding of the extent of poverty and inequality. Hence, such studies are beyond doubt important for the poverty reduction endeavor of the country, whose largest slice of population lives in abject poverty. Besides adding to the body of knowledge on the subject, the output of the study could also be informative for donors and non -governmental organizations 
interested to operate and make intervention in the study area. The study creates awareness for the rural households that in turn enable them design ways to escape poverty. Moreover, the study inform policy making for appropriate interventions and for assessing effectiveness of on-going policy alleviation policies and strategies.

\section{METHODOLOGY OF THE STUDY}

\section{Description Of The Study Area}

Gedeo zone is one of the zones in the Southern Nations, Nationalities and Peoples Region (SNNPR) of Ethiopia. It is located in the North-Eastern part of the region. It lies between 50.59 ' $\mathrm{N}$ and 60.43 ' 'N latitude and 380.40" E and 380.43 " E longitude. The zone has three agro-ecological zones: lowland (Kolla), mid-altitude (Woyina Dega) and highland (Dega) which accounts for $0.5 \%, 70.7 \%$, and $28.8 \%$ respectively. It is shares boundary with Oromia region in the south, southwest and east directions and Sidama zone in the north direction. Dilla town is the administrative capital of the Zone, $360 \mathrm{k} . \mathrm{m}$ from Addis Ababa. The zone has a total population of $1,040,829$ with an area of $1,352.40$ square kilometers with average population density of 774 persons per sq.k.m(Gedeo Zone Finance And Development Bureau,2015).

\section{Research Design}

Cross sectional survey design was employed in this study with both with quantitative approach. Survey methods are extremely efficient in terms of providing large amounts of data at relatively low cost in a short period of time, and has come to be virtually synonymous with social scientific methodology (Smith, 1975). It entails the collection of data on more than one case and at a single point in time in order to collect data. Furthermore, the design for it requires only a snapshot, is less time consuming and cheaper than others( Ravallion and Bidani,1994) indicated how well a cross sectional study design works in identifying chronically rural poor households.

\section{Sampling Techniques and Sample Size}

The method of sampling technique applied in this study was multi-stage sampling and households were the sampling units. At the first stage, Wonago and Kochere woredas of Gedeo zone were selected purposively based on that poverty prevails in the study area based on researcher's observation and their socio-economic profile. In the second stage, six kebles were selected using simple random sampling( 3 kebeles from each woreda). Finally, a probability proportional to sample size (PPS) sampling procedure was employed and 334 sample households (186 from Wonago and 138 from Kochere) woredas were selected using systematic random sampling from the list of the rural households. Therefore, the sampling units have equal chance of being included, and hence representativeness would be ensured. The sample size of each kebele was decided based on proportional sampling technique.

The sample size $\mathrm{n}$ for the study was determined using the following formula (Cochran, 1977) as:

$$
n=\frac{\frac{Z^{2} \alpha / 2 P(1-P)}{d^{2}}}{1+\frac{1}{N}\left(\frac{Z^{2} \alpha / 2 P(1-P)}{d^{2}}-1\right)} \text {; }
$$

Where; $\mathrm{d}$ is the absolute precision, and $Z_{\alpha / 2}$ is value of standard normal deviate at level of significance, $\alpha$. The values taken are $\mathrm{P}=0.5,(1-\mathrm{P})=0.5, \mathrm{~d}=0.03$, and $Z_{\alpha} / 2=1.96$ with $\alpha=0.05$. And also $\mathrm{N}=64,920$, as the total rural households in Wonago and Kochore woredas respectively were 30,599 and 34,321.

Then, when we substitute these values in the above formula, the sample size determined was $n=334$. And, the sample size of households for the randomly selected kebeles for the study was determined proportionally using the method of probability proportional to sample size (PPS) technique. The six kebeles included in the study were Sugale, Tokicha and Mekonisa( from Wonago woreda ) and Baya, Haniku and Biloya( from Kochore woreda).

\section{Data Sources And Methods of Collection}

Both primary and secondary sources were used to collect data for the study. For the primary data, sample households were interviewed by using semi-structured survey questionnaire. This enables to ascertain both subjective and objective facts (Mayntz, 1976). The secondary data was also collected from secondary sources such as reports for triangulation purposes. White (2002) indicates that using triangulation approaches together yields synergy in research. 


\section{Model Specification and Estimation Procedure}

The poverty line was constructed using the Cost of Basic Needs (CBN) model which is the most common method of constructing the absolute poverty line. In this approach, the predetermined normative nutritional requirement of calories was used. In line with this, the minimum requirement of 2,200 Kcal per adult per day of World Bank standard was used(World Bank,2004). Allowance was given to the non-food expenditure component to estimate the total or absolute poverty line by dividing the food poverty line by the average food share for households that enabled a food consumption level equal to food poverty line.

The poverty measure is a statistical function that translates the comparison of the indicator of household well-being and the chosen poverty line into one aggregate number for the population. More precisely, these measures can be defined in terms of the well-known Foster, Greer, and Thorbecke (1984),FGT P $\alpha$ class of poverty measures. This class of poverty index is the most commonly applied to measure poverty. Given a vector of suitable measure of well-being, income(Y), in an increasing order, Y1, Y2, Y3,.., Yn, where $n$ represents the

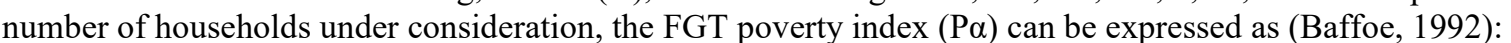

$$
\mathbf{P \alpha}=\frac{1}{N} \sum_{i=1}^{q}\left(\frac{g^{i}}{Z}\right)^{\alpha}
$$

$$
\alpha \geq 0
$$

Where $\mathrm{z}$ is poverty line, $\mathrm{q}$ is the number of the poor, $\mathrm{g}_{\mathrm{i}}$ is shortfall the $\mathrm{i}^{\mathrm{t}}$ household in chosen indicator of wellbeing. If, for instance, $x_{i}$ denote the per capita calorie intake of household $i$, then $g_{i}=z_{i}-x_{i}$ if $x_{i}<z_{;} ; g_{i}=0$ if $x_{i}$ $\geq \mathrm{z}$, and $\alpha$ is the poverty aversion parameter $(\alpha \geq 0)$ which reflects the policymaker's degree of aversion to inequality among the poor. The parameter $\alpha$ represents the weight attached to a gain by the poorest. The commonly used values of $\alpha$ are 0,1 , and 2 . When we set $\alpha$ equal to 0 , then above equation is reduced to the headcount ratio, FGT(0), which measures the incidence of poverty. When we set $\alpha$ equal to 1, we obtain FGT(1) or the poverty deficit.FGT(1) takes in to account how far the poor, on average, are below the poverty line; we also call it poverty gap and it measures depth of poverty. Setting $\alpha$ equal to 2 gives the severity of poverty or FGT(2) index. This poverty index gives greater emphasis to the inequality among the poor that calls for resource redistribution among the poor. The desirable feature of the FGT measures is that they are additively decomposable with population share weights and thus can be expressed as:

$$
\mathrm{P} \alpha(\mathrm{Y} ; \mathrm{Z})=\sum_{i=1}^{m}\left(\frac{n^{j}}{n}\right) P \alpha\left(Y^{j} ; Z\right)
$$

where $Y^{j}$ is the consumption vector of subgroup $\mathrm{j}=1,2, \ldots \mathrm{m}$, and $\mathrm{nj}$ is the population of subgroup $\mathrm{j}$. The additive decomposability of the FGT measures is very useful since it highlights the contribution of different subgroups to poverty. The percentage contribution of subgroup $\mathrm{j}$ to poverty can also be calculated using the following expression: $\left(\frac{n j}{n}\right) P \alpha\left(Y^{j} ; Z\right)$

\section{Methods Of Data Analysis}

First poverty line was calculated using the cost-of-basic-needs(CBN) method. This method is based on the estimated cost of the bundle of goods adequate to ensure that basic needs are met. Establishing a line starts with defining and selecting a 'basket' of food items typically consumed by the rural poor. Based on the food consumption behavior and expenditure pattern of the rural community in the study area a basket of food items typically consumed by the poor was identified. The quantity of the basket is determined in such a way that the given bundle meets the predetermined level of minimum energy intake per day of $2200 \mathrm{kcal} / \mathrm{day}$. The cost of the food bundle was calculated using local market prices to reflect actual food poverty line of the study area. Then after, a specific allowance for the non-food component consistent with the spending patterns of the poor is added to the food poverty line to reach at absolute poverty line. That is the allowance can be made in such way that the food poverty line is divided by the food share of the poorest 25 per cent of the population to arrive at the absolute poverty line. The value of minimum amount of consumed food items at an average price of the identified food items in the local markets plus the sum of estimated minimum amount of money needed to cover the non-food expenses per AE per annum were used as a threshold beyond which the household is said to be poor or non poor.

Once poverty line is set, what follow is poverty measures, which is an index that shows the magnitude of poverty in a society. Kimalu et al., (2002) pointed out that one poverty measure that has been found manageable in presenting information on the poor in an operationally convenient manner is the FGT measure developed by Foster et al., (1984). The FGT poverty measure was applied for analysis. The first step taken has been distinguishing the poor and non poor by constructing poverty line yardstick. People are counted as poor when their measured standard of living is below this line, non-poor otherwise (Rath, 1996). This measure is used to quantify the three well-known elements of poverty: the level, depth and severity (also known, respectively, as incidence, intensity and severity) of poverty. Among these measures, inequality among the rural poor was measured by poverty severity. Based on the (FGT) index of poverty and inequality among the rural households 
would be measured (ISSER, 1993; FAO, 2001; Ravallion,1992)

\section{RESULTS AND DISCUSSIONS}

\section{Calculating Poverty Lines}

The response rate of the questionnaire distributed was about $97 \%$. Accordingly, to examine the levels of poverty and inequality in the study area, the calculation of poverty lines and indices of poverty and inequality were made using 325 sample households rather than 334 sample size. In the study, absolute poverty line is defined on the basis of the cost of obtaining the minimum calorie requirement for subsistence, which is $2200 \mathrm{kcal}$ per adult per day (Ravallion and Bidani, 1994), taking the diet of the lowest income quartile households. The calorie share of the diets to the minimum calorie required for subsistence is calculated to arrive at the level of calorie and quantities of food group items that gives the $2200 \mathrm{kcal}$. Based on these methodological steps of the CBN model the food poverty line and the absolute poverty line that corresponds to the basket of food items were calculated by adopting from EHNRI(2007) and Dercon and Krishnan(1998).

The quantities of the food item groups are valued using average local market prices in order to reflect the actual food poverty line in the locality (table-1). That is, the total poverty line can be obtained by adjusting for non- food expenditure using the average food share of the lowest consumption quartile households. In this regard, the non-food expenditures include expenditures of clothing, medical, education, social obligations (like religious, idir, social contributions, etc. ), housing, transportation, other miscellaneous expenses. Dividing the food poverty line by the average food share of the lowest consumption quartile gives a total poverty line. In this regard, the Food basket composition used for poverty lines (per month) and nutrition (calorie) based equivalence scales for the food items were identified in the study area.

The food poverty line calculated from the data available was found to be Birr 3952.74. Then this food poverty line is divided by the food share of the poorest 25 per cent of the population to arrive at the absolute poverty line. That is, the non-food expenditure component is calculated using the average food share of the lowest income quartile households. The food share of the lowest income quartile is found to be 88.56 percent. This figure is used to estimate an allowance of non-food expenditure and found to be 510.61 Birr. Therefore, the sum of food and non-food expenditures gives absolute poverty line of Birr 4463.35. Therefore, the food and absolute poverty lines for the study area were determined to be Birr 3952.74 and 4463.35, respectively( table-1 ). Compared to the national level poverty lines in 2010/11, both the food and absolute poverty lines in this study were higher where their respective figures were calculated as ETB 1985 and 3781 (MOFED, 2012). This indicated the fact that a typical household in Gedeo zone with a household size of 4.82 adult equivalent units needs an income of Birr 3952.74 per annum which is Birr 820.071 per adult equivalent per annum to escape food poverty. Similarly, with an average household size of 4.82 adult equivalent units, a typical household in the zone needs an income of Birr 4463.35 per annum which is Birr 926.006 per adult equivalent per annum to escape absolute poverty.

Table -1 : Food poverty line based on food basket of 2200 Kcal per adult per day

\begin{tabular}{|c|c|c|c|c|c|c|c|c|c|}
\hline $\begin{array}{l}\text { Food } \\
\text { items }\end{array}$ & $\begin{array}{l}\text { Mean } \\
\text { Kcal/ } \\
100 \\
\text { Gram/Lt }\end{array}$ & $\begin{array}{l}\text { Food } \\
\text { basket } \\
\text { per adult } \\
\text { per } \\
\text { day in } \\
\mathrm{Kg} / \mathrm{Lt}\end{array}$ & $\begin{array}{l}\text { Kcal } \\
\text { per } \\
\text { day } \\
\text { per } \\
\text { adult }\end{array}$ & $\begin{array}{l}\text { Kcal per } \\
\text { adult } \\
\text { per day } \\
\text { needed to } \\
\text { get } \\
2200 \mathrm{Kcal} \\
\end{array}$ & $\begin{array}{l}\text { Kcal } \\
\text { share } \\
(\%)\end{array}$ & $\begin{array}{l}\text { Food } \\
\text { basket } \\
\text { per adult } \\
\text { per } \\
\text { Month in } \\
\mathrm{Kg} / \mathrm{Lt}\end{array}$ & $\begin{array}{l}\text { Mean } \\
\text { price per } \\
\text { Kg/lt(in } \\
\text { ETB) }\end{array}$ & $\begin{array}{l}\text { Cost } \\
\text { per } \\
\text { month } \\
\text { (ETB) }\end{array}$ & $\begin{array}{l}\text { Value of } \\
\text { poverty } \\
\text { line } \\
\text { per year } \\
\text { (Birr) }\end{array}$ \\
\hline Wheat & 357.4 & 0.048 & 171.55 & 243.895 & 11.09 & 1.44 & 11 & 15.84 & 190.08 \\
\hline Barely & 372.3 & 0.058 & 215.93 & 306.993 & 13.95 & 1.74 & 9 & 15.66 & 187.92 \\
\hline Teff & 355.1 & 0.099 & 351.55 & 499.797 & 22.72 & 2.97 & 14.50 & 43.07 & 516.78 \\
\hline Maize & 375 & 0.047 & 176.25 & 250.574 & 11.39 & 1.41 & 6.50 & 9.17 & 109.98 \\
\hline Beans & 351.4 & 0.054 & 189.76 & 269.776 & 12.26 & 1.62 & 12.5 & 20.25 & 243.00 \\
\hline Peas & 355.3 & 0.009 & 31.98 & 45.462 & 2.07 & 0.27 & 15.5 & 4.19 & 50.22 \\
\hline Onion & 71.3 & 0.026 & 18.54 & 26.355 & 1.20 & 0.78 & 11 & 8.58 & 102.96 \\
\hline Tomatoes & 30.7 & 0.013 & 3.99 & 5.674 & 0.26 & 0.39 & 12.33 & 4.81 & 57.70 \\
\hline Potatoes & 89.7 & 0.024 & 21.53 & 30.606 & 1.39 & 0.72 & 6.5 & 4.68 & 56.16 \\
\hline Cabbage & 23.7 & 0.009 & 2.13 & 3.032 & 0.14 & 0.27 & 5.50 & 1.49 & 17.82 \\
\hline Pepper & 360.1 & 0.012 & 43.21 & 61.434 & 2.79 & 0.36 & 77.5 & 27.90 & 334.80 \\
\hline Coffee & 110.3 & 0.008 & 8.82 & 12.545 & 0.57 & 0.24 & 58.60 & 14.06 & 168.77 \\
\hline Sugar & 385 & 0.012 & 46.20 & 65.682 & 2.99 & 0.36 & 15.2 & 5.47 & 65.66 \\
\hline Salt & 178 & 0.013 & 23.14 & 32.898 & 1.50 & 0.39 & 5.0 & 1.95 & 23.40 \\
\hline Oil & 896.4 & 0.014 & 125.50 & 178.417 & 8.11 & 0.42 & 24.60 & 10.33 & 123.98 \\
\hline Milk & 73.7 & 0.014 & 10.32 & 14.669 & 0.67 & 0.42 & 15 & 6.30 & 75.60 \\
\hline
\end{tabular}




\begin{tabular}{|l|l|l|l|l|l|l|l|l|l|}
\hline $\begin{array}{l}\text { Food } \\
\text { items }\end{array}$ & $\begin{array}{l}\text { Mean } \\
\text { Kcal/ } \\
100 \\
\text { Gram/Lt }\end{array}$ & $\begin{array}{l}\text { Food } \\
\text { basket } \\
\text { per adult } \\
\text { per } \\
\text { day in } \\
\text { Kg/Lt }\end{array}$ & $\begin{array}{l}\text { Kcal } \\
\text { per } \\
\text { day } \\
\text { per } \\
\text { adult }\end{array}$ & $\begin{array}{l}\text { Kcal per } \\
\text { adult } \\
\text { per day } \\
\text { needed to } \\
\text { get } \\
2200 \mathrm{Kcal}\end{array}$ & $\begin{array}{l}\text { Kcal } \\
\text { share } \\
(\%)\end{array}$ & $\begin{array}{l}\text { Food } \\
\text { basket } \\
\text { per adult } \\
\text { per } \\
\text { Month in } \\
\text { Kg/Lt }\end{array}$ & $\begin{array}{l}\text { Mean } \\
\text { price per } \\
\text { Kg/lt(in } \\
\text { ETB) }\end{array}$ & $\begin{array}{l}\text { Cost } \\
\text { per } \\
\text { month } \\
\text { (ETB) }\end{array}$ & $\begin{array}{l}\text { Value of } \\
\text { poverty } \\
\text { line } \\
\text { per year } \\
\text { (Birr) }\end{array}$ \\
\hline Enset & 18.1 & 0.006 & 1.09 & 1.544 & 0.07 & 0.18 & 8.40 & 1.51 & 18.14 \\
\hline meat & 197 & 0.033 & 65.01 & 92.425 & 4.20 & 0.99 & 107.5 & 106.43 & 1277.10 \\
\hline banana & 87.8 & 0.027 & 23.71 & 33.708 & 1.53 & 0.81 & 10.40 & 8.42 & 101.09 \\
\hline Carrot & 42.0 & 0.018 & 7.56 & 10.748 & 0.49 & 0.54 & 9 & 4.86 & 58.32 \\
\hline Garlic & 138.3 & 0.007 & 9.68 & 13.763 & 0.63 & 0.21 & 68.75 & 14.44 & 173.25 \\
\hline & & & & & & & & & $\mathbf{3 9 5 2 . 7 4}$ \\
\hline
\end{tabular}

Source: Own computation based on the survey,2016

\section{Poverty Measures and Its Magnitude}

The poverty lines and the per adult consumption expenditure are used to aggregate consumption poverty indices. The per adult consumption is obtained by first dividing the total consumption expenditure by nutritional calorie based adult equivalence (AE) family size to arrive at per adult consumption expenditure. The per adult consumption expenditure includes both food and non-food consumption expenditures measured at current average prices in the study area. The study revealed that the mean consumption expenditure for the sample households is Birr 6904.38 /AE. The minimum and maximum consumption expenditure per AE during study period were Birr 1436.00 and 20776.00 respectively. The respective mean consumption expenditure for the poor and non poor group swas Birr 4076.47 and 8125.23. This shows that there was a significant difference between the two means at $1 \%$ probability level (table-2) in terms of distribution of consumption expenditure.

Table-2 :Distribution of Sample Households Consumption Expenditure per year (in ETB)

\begin{tabular}{|c|c|c|c|c|c|c|c|}
\hline \multirow[t]{2}{*}{ Birr/AE } & \multicolumn{2}{|c|}{ Poor $(n=98)$} & \multicolumn{2}{|c|}{ Non Poor $(n=227)$} & \multirow{3}{*}{ t- value } & \multicolumn{2}{|c|}{ Total $(\mathrm{n}=325)$} \\
\hline & No & Percent & No & Percent & & No & Cum. Percent \\
\hline$<1,464$ & 6 & 6.12 & & & & 11 & 3.38 \\
\hline $1,464-2,963$ & 12 & 12.24 & & & & 32 & 13.23 \\
\hline $2,964-4,463$ & 80 & 81.63 & & & & 55 & 30.14 \\
\hline $4,464-5,963$ & & & 43 & 18.94 & & 43 & 43.37 \\
\hline $5,964-7,463$ & & & 51 & 22.47 & & 51 & 59.07 \\
\hline $7,464-8,963$ & & & 62 & 27.31 & & 62 & 78.14 \\
\hline $8,964-10,463$ & & & 54 & 23.79 & & 54 & 94.74 \\
\hline$>10,463$ & & & 17 & 7.49 & & 17 & 100 \\
\hline Min (Birr/AE) & 1436 & & & & & 143 & \\
\hline Max (Birr/AE) & $446 ?$ & & 207 & & & 207 & \\
\hline Mean (Birr/AE) & 4076 & & 812 & & $25.488^{*}$ & 690 & \\
\hline Std.Dev (Birr/AE) & 825. & & 239 & & & 276 & \\
\hline
\end{tabular}

Source: Own Survey Result, 2016

* Significant at $1 \%$ probability level

The poverty measure $(\mathrm{P} \alpha)$ developed by Foster, Greer and Thorbecke (1983) were used to explain the extent of poverty in the study area. Poverty indices were computed based on the consumption expenditures. The resulting poverty estimates for the study area (table-3) shows that the percentage of poor people measured in absolute head count index $(\alpha=0)$ was about $30.2 \%$. This figure indicates that this proportion of the sampled households in Gedeo zone live below absolute poverty line. This implies that $30.2 \%$. of the population are unable to get the minimum calorie required $(2200 \mathrm{kcal}$ per day per adult) adjusted for the requirement of nonfood items expenditure. Putting it differently, this proportion of rural community in Gedeo zone are unable to fulfill the minimum amount of income i.e., Birr 4463 per adult equivalent per year and live under absolute poverty. The poverty gap index $(\alpha=1)$, a measure that captures the mean aggregate consumption shortfall relative to the poverty line across the sample population is found to be 0.085 which means that the percentage of total consumption needed to bring the entire population to the poverty line is $8.5 \%$. Similarly, the FGT poverty severity index (the squared poverty gap, $\alpha=2$ ) in consumption expenditure shows that $3.4 \%$ fall below the threshold line implying severe inequality among the rural poor. In other words, it means that there is a high degree of inequality among the lowest quartile population. Nevertheless, these poverty profile figures have close similarity to that of the poverty indices that were reported in the poverty study in Ethiopia (MoFED, 2012). 
Table-3: Absolute Poverty Indices and Food Poverty Indices of rural Households

\begin{tabular}{|l|c|l|c|}
\hline \multicolumn{2}{|c|}{ Absolute Poverty } & \multicolumn{2}{c|}{ Food Poverty } \\
\hline Poverty indices & Index values & Poverty indices & Index values \\
\hline Head count index $(\alpha=0)$ & 0.302 & Head count index $(\alpha=0)$ & 0.052 \\
\hline Poverty gap $(\alpha=1)$ & 0.085 & Poverty gap $(\alpha=1)$ & 0.021 \\
\hline poverty severity $(\alpha=2)$ & 0.034 & poverty severity $(\alpha=2)$ & 0.010 \\
\hline
\end{tabular}

Source: Own survey computation, 2017

In addition to the absolute poverty indices, the food poverty measures are computed for the sample households. The food poverty index measures the proportion of food-poor people that fall below the food poverty line. The proportion of food poor people (food poverty head count index) in the country was estimated to be $5.2 \%$ during the study period. The food poverty gap index was also estimated to be $2.1 \%$.Similarly, the food poverty severity index stood at $1 \%$. This poverty results indicate that food poverty is much lower than absolute poverty. These results showed that all kinds food poverty indices (incidence, depth and severity) are lower than the absolute poverty measures (table-3). As achievement of food self-sufficiency has been one of the key objectives of the Ethiopian government as articulated in its GTP and rural development policies and strategies, which is also consistent with the SDG goal of eradicating extreme poverty or hunger, such very low food poverty may be attributed to the wide-ranging and multi-faceted pro-poor programs of the government that have been implemented in rural areas such as intensification of agriculture, rural infrastructural development and food security programs.

Moreover, the food and non-food expenditure pattern and categories of rural sample households was analyzed. The results of the study showed that the poor in the study were found to spend larger proportion of their expenditure on food (about 88 percent) than the non-poor which was( about 85 percent). This is in line with Engel's law, which states that relative to the non-poor, the poor spend higher proportion of their income on food. This result is consistent with Metalign(2005).

\section{CONCLUSION}

Cost of basic needs(CBN) approach and FGT measures have been employed to set the poverty line(both food and absolute) and compute the magnitude(incidence, gap and severity) of rural poverty in the study respectively. The food and absolute poverty lines were calculated based on food basket of 2200 Kcal per adult per day. Accordingly, the food and absolute poverty lines for the study area are determined to be Birr 3952.74 and 4463.35 , respectively. Compared to the national level poverty lines in 2011 , both the food and absolute poverty lines in this study were higher where the national respective figures in the same period were ETB 1985 and 3781. The food expenditure takes the lion's share accounting for about $88.56 \%$ (relative to the non-food expenditure) in the consumption expenditure of the poor and thus this substantial expenditure was used for estimating the poverty line. Thereafter, the poverty indices were computed using FGT indices. The incidence, depth and severity of food poverty stood at $0.052,0.021,0.010$, while measures for absolute poverty were found to be $0.302,0.085$ and 0.034 . These all indices confirm that food and absolute poverty have been problems and remain a major concerns that needs great attention in policy making and designing strategies in rural development.

\section{RECOMMENDATIONS}

- The measures of poverty and inequality among the rural households in the study area indicates that the overall magnitude of poverty is quite significant and needs further attention from all stake holders working on rural development such as national and regional governments, civil society organizations, donors, the local community and other development partners .

- Considering the multidimensional poverty, a clear prioritization of multitude measures for interventions is needed to address poverty in the rural Gedeo Zone as the narrow approach such as income or expenditure may not sufficiently address the problem of poor.

- Besides, Policies on overall rural livelihood improvements have to be implemented. In this regard evidence is mounting that Ethiopian government works aggressively and has shown progress in rural poverty reduction though the result of the study witnesses that much more work is required to address poverty and improve the living standards of the rural community.

\section{REFERENCES}

Aigbokhan, E. Ben (2000). Poverty, Growth and Inequity in Nigeria: A Case Study. AERC Research Paper 102. Development policy Centre, Ibadan, Nigeria.

Baffae, J. K., 1992. Income Distribution and Poverty Profile in Ghana 1987 . 1988. African Development Review, 4(1), 1.28.

Cochran, W. G.(1977) . Sampling techniques (3rd ed.). New York: John Wiley \& Sons.

Dercon Stephan and Krishnan Pramila (1998). A Consumption-Based Measure of Poverty for Rural Ethiopia in 
1989 and 1994. In Bereket K. and Mokonen T. (Eds.). The Ethiopian Economy: Poverty and Poverty Alleviation. Proceedings of the Fifth Annual Conference on the Ethiopian Economy. Addis Ababa.

EHNRI, Ethiopian Health and Nutrition Research Institute (2007). Food Composition Table for Use in Ethiopia. Addis Ababa.

FAO (2001). Food, Agricultural and rural Development .Current and Emerging Issues for Economic Analysis and Policy Research, Economic and Social Department,(ed.) Stamoulis, K.G. FAO: Rome

Foster, Greer and Thorbecke, (1984). A Class of Decomposable Poverty Measures.

Gedeo Zone Finance And Development Bureau(2015). Report on socio economic Survey Report, SNNR State, Ethiopia .Dilla.

ISSER (Institute of Statistical, Social and Economic Research). (1993). Policies and Options for Ghanaian Economic Development, Nyanteng, V.K. (ed). ISSER, University of Ghana, Legion.

Kimalu, Paul et al., (2002). A Situational Analysis of Poverty in Kenya. The Kenyan Institute for Public Policy Research and Analysis (KIPPRA) Working Paper Series. WP/6/2002.

Mayntz R., Holm K. and Huebner R. (1976). Introduction to Empirical Sociology. Penguin Books Canada Ltd. Ontario.

MEDaC. (1999). Survey of the Ethiopian Economy: Review of post- Reform Development (1992/93-1997/98). Ministry of Economic Development and Cooperation (MEDaC). Addis Ababa.

Metalign, A. (2005). Rural poverty situation and determinants: The case of Kersa Kondalitity Woreda, South West Shewa. Unpublished Masters degree thesis at the Institute of Regional and Local development Studies, Addis Ababa University.

MoFED( 2012). Ethiopia's Progress Towards Eradicating Poverty: An Interim Report on Poverty Analysis Study . Development Planning and Research Directorate. Ministry of Finance and Economic Development, Addis Ababa.

NBE (National Bank of Ethiopia) (2017/18). Annual Report 2017. Addis Ababa, Ethiopia

NPC. (2017). The 2017 Voluntary National Reviews on SDGs of Ethiopia: Government Commitments, National Ownership and PerformanceTrends.

Rath, N. (1996). Indian Journal of Agricultural Economics: Poverty in India Revisited. pp. 76- 109. Indian Society of Agricultural Economics, Numbai

Ravallion, M. (1992). Poverty Comparison: A guide to Concepts and Methods. Living Standard Measurement Study. The World Bank, Washington, D.C.

Ravallion, M. and Bidani, B (1994). How Robust is a Poverty Profile? World Bank Economic Review. Volume 8, No. 1.

Schubert, R. 1994. Poverty in Developing Countries: Its Definition, Extent and Implications, Economics 49/50.

Smith, H.W. (1975). Strategies of Social Research: The Methodological Imagination. Prentice-Hall, Inc, U.S.A.

Tassew Woldehanna (2004). New Pro-Poor Policies, Pre PRSP Experiences and the 2003-04 .Budget in Relation to Agriculture and Food Security in Ethiopia.

Todaro, M.P. (1997). Economic Development, 6th edition, Third impression. New York.

White, H. (2002). Combining Quantitative and Qualitative Approaches in Poverty Analysis. World Development $30(3)$.

World Bank (2004). Rural Development Indicators Handbook. WBI, 2004.

World Bank(2017). Global Economic Prospects: Regional Overview, Sub -Saharan,2017 